the United States, of an importation of a real spiritualistic mania, far more injurious to our mental welfare, than that of the Colorado beetle will be to our material interests, I should be untrue to my own convictions of duty if I did not do what in me lies to prevent it. That I do not take an exaggerated view of the danger, will be obvious to any reader of $\mathrm{Mr}$. Home's book. I know too well that I thus expose myself to severe obloquy, which (as I am 'not peculiarly thick-skinned) will be very unpleasant to myself, and unfortunately still more so to some who are nearly connected with me. But I am content to brave all, if I can believe that my exposé will be of the least service either to individuals or to society at large.

W. B. Carpenter

THE high scientific position which Prof. Foster holds, as well as the decided manner in which his letter was written, must lead the otherwise unbiassed reader to the conclusion that not only has a satisfactory explanation of the action in question been found and generally adopted, but that this explanation turns upon certain considerations, and particularly on the mean length of the path of the gaseous molecules as influenced by the degree of rarefaction.

I feel my position, therefore, particularly unfortunate in having, for the sake of truth, to show that the explanation which Prof. Foster has adopted, and supposes others to have adopted, is, if judged by the statements in his letter, inconsistent with well-established laws.

Prof. Foster gives me credit for having originated the fundamental idea of the explanation, but states that my "explanation was theoretically incomplete; in particular it did not show clearly why so high a degree of rarefaction should be necessary for the production of the phenomenon in question ; " and then he proceeds to explain how this asserted deficiency was supplied by other thinkers, who showed that "the increase, resulting from rarefaction, in the mean length of the path of the gaseous molecules, would favour the action."

It is this supposed completion of my explanation that is erroneous. It is contrary to the law of the diffusion of heat in gases that "the increase, resulting from rarefaction, in the mean length of the path of the gaseous molecules would favour the action," and so far from supplying any deficiency in my explanation it is incompatible with it. The only result from such an increase is to diminish the action-a result which rises into importance only when the rarefaction is carried so far that the mean length of the path of a molecule becomes comparable with the dimensions of the inclosing vessel.

In my first paper I gave a definite proof, which has nowhere been questioned, that according to the kinetic theory the force arising from the communication of heat from a surface to adjacent gas of any particular kind depends only on one thing, the rate at which heat is communicated, and to this it is proportional. If therefore the increased rarefaction increased the $f$ rice it must increase the rate at which heat is communicated, but according to the law established by Prof. Maxwell the rate at which heat is communicated is independent of the density of the gas, whence it follows that the increase in the mean length of the path of the gaseous molecules, resulting from rarefaction, cannot favour the action which remains approximately constant until the gas becomes so rare that the law of diffusion no longer holds, atter which it may easily be shown the communication of heat, and hence the action in question, diminishes but never increases.

The fact that in the radiometer the force caused by the communication of heat only causes motion when the surrounding gas becomes extremely rare is, as I pointed out in my first papers, fully explained by the action of what $I$ have called convection currents, which action depends on the weight and density of the gas. The gas adjacent to the hot surface is hotter than that which is more remote, and hence the former rises forming an ascending column, to supply which the gas is drawn in laterally on all sides, and tends to carry the surface forward with it. With the same difference of temperature and surrounding circumstances the speed of these convection currents is the same whatever may be the density of the gas, and hence the force which they exert on the surface is proportional to the density of the gas.

This force is opposite in direction to that arising from the communica: ion of heat to the gas, and since the former diminishes with the density while the latter is constant, there must be some density for which they balance, and below which the constant force will predominate, while above this point the convection currents will carry the surface with them. The fact that, starting from low densities, the motion of the vanes in the radiometer does not only diminish as the density increases, but is actually reversed at higher densities, requires explanation, and no other than this has yet been offered.

I have gone into the subject at considerable length, as I felt bound, when venturing to differ from so high an authority as Prof. Foster, to state my reasons. There is, however, nothing in what I have said here which I have not said elsewhere, in the same or other words; and however incomplete in theory the explanation given in my first papers may be, I can only say that it included all the facts known to me at the time these were written; it has led me to predict many of the experimental results which have since been obtained, and I have not been able to find one fact with which it is not in accordance, nor has it been, so far as I am aware, controverted in any particular.

OSBORNE REYNOLDS

\section{Potential Energy}

I HAVE reason to believe that the "grievous error" with which I charged "John O'Toole" in his reference to the clock is not meant by him to be his own view of the matter at all, but merely a legitimate deduction from the confused and inconsistent language of "the doctors." Such an erroneous view on his part is, indeed, obviously out of harmony with the extensive knowledge of the subject of energy displayed by him in letters which, without doubt, will convince "the doctors" of the necessity of adopting consistent and strictly logical phraseology.

Royal Indian Engineering College, Cooper's Hill G. M. Minchin \section{Effects of Urticating Organs of Millepora on the}

An article by Mr. Moseley, in NarURe (vol. xvi. p. 475), reminds me of an experiment I made some years ago in Florida. In collecting corals on the reefs, I had of course become familiar with the disagreeable, though not very painfui, effects of contact of the hands with Millepora. But the vulgar names of Pepper-coral or Sea ginger indused me to try the effect on the tongue, to find out how far the taste resembled those condiments. I accordingly broke off a fresh piece and applied it to the tongue. Instantly a most severe pain shot, not only through that organ, but also through the jaws and teeth. The whole course of the dental nerves and their ramifications into every single tooth could be distinctly and painfully telt. I can compare the sensation to nuthing Detter than to the application of the poles of a pretty strong galvanic battery. The pain remained severe for about half an hour, then became duller, leaving a sensation still perceptible five or six hours later. The whole impression was much too vislent to allow the distinction of any particular taste.

Such an experiment made with Physalia might be positively dangerous, considering the much more powerful urticating effects of its polyps. Indeed, a friend of mine once related to me that when a boy he had come in contact with one of the long tentacles of a Physalia, when bathing, and had to be carried out of the water almost fainting.

Cambridge, Mass., October 22

L. F. Pourtales

\section{Drowned by a Devil Fish}

THE following account of the destruction of a human being by a cuttle fish at Victoria, in Vancouver Island, has all the appearance of authenticity about it. It occurs in the Weekly Oregonian of October 6, 1877 . The Oregonian is the principal paper of Oregon, and is published at Portland.

The insertion of the account in NATURE may lead to further information on the subject. I know of no other authentic instance of the kind.

An account of the habits of the huge octopus of the Vancouver Island Sounds and also of the Indian method of hunting and killing the beasts for food is to be found in John Keast Lord's "Naturalist in Vancouver Island and British Columbia," vol, i. p. 192. Mr. Lord measured specimens which had arms five feet in length, with a thickness at their base as great as his wrist, and he once collected a detached sucker of one of these cephalopods as large as an egg cup in mistake for a huge actinia. 